\title{
Sleep duration, snoring habits and risk of acute myocardial infarction in China population: results of the INTERHEART study
}

Dongfang Xie ${ }^{1}$, Wei Li ${ }^{1 *}$, Yang Wang ${ }^{1}$, Hongqiu Gu${ }^{1}$, Koon Teo ${ }^{3}$, Lisheng Liư ${ }^{1,2}$, Salim Yusuf ${ }^{3}$ and on behalf of the INTERHEART China study Investigators

\begin{abstract}
Background: Less sleep time and snoring have been associated with cardiovascular disease (CVD) risk in Western populations; however, few studies have evaluated the different aspects of sleep duration and snoring frequency in relation to CVD, and this association has not been examined in China. The present study aimed to address the relation between sleep duration, snoring frequency and risk of acute myocardial infarction (AMI) in China population.

Methods: We conducted a hospital-based case-control study. Cases were first AMI $(n=2909)$. Controls were matched to cases on age and sex. 2947 controls who did not report previous angina or physical disability completed a questionnaire on sleep duration and snoring frequency. We used logistic regression to control for other risk factors.

Results: We observed an inverse association between serious snoring frequency and AMl risk. After adjustment for all the risk factors, and the OR for everyday group and 3-5 times per week group was 1.45 (95\% Cl: 1.01 to 1.91) and 1.93 (95\% Cl: 1.52-2.46) compared to no snoring group. The OR for serious level group and moderate group was 1.77 (95\% Cl: 1.29 to 2.43 ) and 1.37 (95\% Cl: 1.10 to 1.69$)$ compared to no snoring group. People having serious snoring increased $77 \%$ risk of AMI. 15.2\% people in control group have $\leq 6$ hours sleeping, compared with $17.4 \%$ in AMl group.

Conclusions: Snoring frequency, including as much as everyday and 3-5 times per week, was positively associated with $\mathrm{AMI}$ risk and less sleep duration was associated with risk of AMI. Less sleep time could increase AMI risk in China population.
\end{abstract}

Keywords: Cardiovascular disease, Snoring, Sleep, Acute myocardial infarction, China

\section{Background}

Cardiovascular disease (CVD) is the leading cause of death and disability-adjusted life-years world wide, with increasing incidence and prevalence in low- and middleincome countries. By 2020, more than $80 \%$ of global CVD will be in these countries, with the largest burden occurring in the two largest countries, China and India, as they rapidly urbanise [1].

\footnotetext{
* Correspondence: liwei@mrbc-nccd.com

'Division of Biometrics, National Center for Cardiovascular Diseases, Cardiovascular Institute \& Fu Wai Hospital, Peking Union Medical College \& Chinese Academy of Medical Sciences, Beijing 100037, China Full list of author information is available at the end of the article
}

Sleep duration has been associated with CVD, stroke, diabetes, hypertension, and all-cause mortality [2-13]. A recent meta-analysis documented that compared with 7 hours of sleep, shorter duration of sleep was associated with up to a 2-fold increased risk for CVD-related mortality [2]. For both men and women, lack of sleep has been associated with increased risk of cardiovascular events $[5,6]$. Amagai et al. 3 showed that sleeping less than 6 hours per night, when compared with sleeping 7 to 7.9 hours per night, was associated with CVD risk of 2.14 for men and 1.46 for women. Understanding the relation between lack of sleep and adverse health effects is important because over the last 30 years, diminished 
sleep duration ( $<6$ hours) has increased from $7.6 \%$ of the population in 1975 to $9.3 \%$ in 2006 [14]. Potential mechanisms for the relation between inadequate sleep and increased cardiovascular risk include up-regulation of appetite and decreased energy expenditure, leading to obesity and its metabolic consequences, and alterations in glucose metabolism $[15,16]$.

Associations of snoring with cardiovascular disease was examined cross-sectionally $[17,18]$ in clinical and largescale epidemiologic studies, most of which clearly showed an independent positive association, even after adjustment for potential confounding factors such as age, sex, and body mass index (BMI) [19]. This causal relationship has also been observed in studies of Western populations. As compared with non-snorers, the relative risk of developing cardiovascular disease among habitual snoring American women was 30\% higher in the Nurses' Health Study [20], and the risk among habitual and frequent snoring Finish men was 2.1-fold higher [21]. However, evidence from Asian populations is still very limited, and these results from Western studies cannot simply be extrapolated to Asian populations.

The purpose of this study was to assess the association between sleep habits, defined as sleep duration and snoring, and measured risk factors for CVD in China population, including both traditional and psychosocial risk factors. An additional aim of the research was to evaluate the potential mechanisms related to sleep habits and cardiovascular risk as well as to assess any interaction by gender or age.

\section{Methods}

\section{Study population}

INTERHEART China study is a case-control study. In the study, 2909 patients with incident cases of acute myocardial infarction (AMI) and 2947 control subjects free of heart disease from 27 regions in China were enrolled between February 1999 and March 2003.

To identify first cases of acute myocardial infarction, all patients (irrespective of age) admitted to the coronary care unit or equivalent cardiology ward, presenting within $24 \mathrm{~h}$ of symptom onset, were screened. Cases were eligible if they had characteristic symptoms plus electrocardiogram changes indicative of a new myocardial infarction. At least one age- $( \pm 5$ years $)$ and sex-matched control (without a history of CVD) was recruited for each case from non-cardiac wards or unrelated visitors of cardiac patients, or patients at the same centers with illnesses not obviously related to CVD or its risk factors. At entry to the study, informed consent was obtained from each subject. This study was approved by appropriate regulatory and ethics councils in all participating centers. A structured and pre-tested questionnaire was administered and physical examinations were undertaken in the same manner among cases and controls [22-24].

\section{Ethical approval and informed consent}

Subjects willing to participate are subsequently sent written information on the study procedures along with an informed consent form. Only participants providing written informed consent are enrolled. Ethical approval was obtained by the Medical Ethical Committee of Beijing Fu Wai Hospital.

\section{Procedures}

Trained personnel administered the structured questionnaires and physical examinations in a standardized manner. Information about demographic factors, family income and education, lifestyle, personal and family history of CVD and risk factors, psychosocial factors, physical activities, and smoking history, alcohol use were obtained with the use of standardized INTERHEART questionnaires. Personal and family patterns of cardiovascular disease (CVD) and risk factors were recorded, and histories of hypertension and diabetes were self-reported. Three categories of educational level were created: none or 1-8 years, 9-12 years, trade school or college or university. Family income defined as three groups. Three categories were lower group ( $\leq 6000$ yuan/year), middle group (6000-10000 yuan/ year), and higher group ( $\geq 10000$ yuan/year) according to the level of income. Questions were included about psychosocial conditions to identify depressive mood and psychological stress. General psychological stress was defined as experiencing stress at work or at home and was also assessed in the four categories. Subjects were asked whether they had suffered from some Stressful life events in the previous year, including marital separation/ divorce, loss of job/retirement, loss of crop/business failure, violence, major intra-family conflict, major personal injury or illness, death/major illness of a close family member, death of a spouse and other major stress. Blood pressure, height, weight, waist and hip circumferences were measured. Body mass index (BMI) was defined as weight (kg) divided by squared height $\left(\mathrm{m}^{2}\right)$.

During the INTERHEART examination, a self-administered sleep history questionnaire was obtained. Among the questions were a) "Have you ever snored (now or at any time in the past)?"; if yes, "How frequent and loudly do you snore?"; b) "How long your night's sleep?" Participants were provided 4 responses to each question: $\leq 6$, 6-8, > 8, don't know; and c) "Do you have the habit of napping?"; if yes, "How long do you nap everyday?". Among the INTERHEART participants, who did not report "don't know" to either the sleep or snoring questions and were therefore excluded from this analysis. 


\section{Statistical analysis}

Clinical data of continuous variables expressed as mean (SD) and differences were assessed by rank test. Categorical variables were represented as percentage and were tested by Pearson chi-squared analysis.

The association between sleep, snoring frequency and AMI was assessed in several different ways. In models which adjusted for age, sex and area, we investigated the effect on each variable on the risk of AMI. Subsequently, multivariable logistic regression models were built where, after adjustment for age and sex, we separately introduced (1) age, sex, BMI, hypertension, diabetes, stroke and family history of MI. (2) age, sex, area, WHR, BMI, smoking, drinking, physical activity, consumption of vegetables and fruits. (3) age, sex, area, educational status, household income, marital status, stress and depression. Age, BMI, and whr levels were approximate a normal distribution. $P<0.05$ was used to indicate statistically significant differences. Significance was assessed by a Wald test and by a likelihood-ratio test.

During this process, we explored the interaction between snoring frequency and other risk factors. The Wald chi-square test was used to test the interaction.

All statistical tests were two-sided. Statistical analyses and graphics were produced with the SAS software version 9.1.3 and Excel.

\section{Results}

In the INTERHEART China study, cases and controls, matched by age and gender, were enrolled between February

\section{Table 1 Characteristics of participants}

\begin{tabular}{|c|c|c|c|c|}
\hline Characteristics & AMI cases, $N=2909$ & Controls, $N=2947$ & $x^{2} / Z$ & $P$-value \\
\hline Male sex (\%) & $2027(69.7)$ & $2048(69.5)$ & 0.02 & 0.8771 \\
\hline Mean Age (SD), year & $62.1(11.7)$ & $60.3(11.4)$ & 6.28 & 0.0001 \\
\hline BMI, n (\%) & & & 18.40 & 0.0001 \\
\hline$\leq 24$ & $1173(40.3)$ & $1341(45.5)$ & & \\
\hline $24-28$ & $1358(46.7)$ & $1291(43.8)$ & & \\
\hline$>28$ & $378(13.0)$ & $315(10.7)$ & & \\
\hline WHR, mean (SD), $\mathrm{cm} / \mathrm{cm}$ & $0.88(0.08)$ & $0.88(0.08)$ & 2.16 & 0.2011 \\
\hline Hypertension (\%) & $1145(39.5)$ & $656(22.26)$ & 203.68 & 0.0001 \\
\hline Diabetes (\%) & $360(12.4)$ & $87(3.0)$ & 185.54 & 0.0001 \\
\hline Stroke (\%) & 317 (10.9) & $102(3.5)$ & 122.76 & 0.0001 \\
\hline Family history of Ml, n (\%) & $102(3.5)$ & $54(1.8)$ & 15.93 & 0.0001 \\
\hline Smoking, n (\%) & $1694(58.2)$ & $1186(40.2)$ & 189.54 & 0.0001 \\
\hline Alcohol, n (\%) & $463(15.9)$ & $429(14.6)$ & 2.09 & 0.1479 \\
\hline Physical activity, n (\%) & $128(14.8)$ & $558(19.0)$ & 17.93 & 0.0001 \\
\hline Educational status, n (\%) & & & 52.57 & 0.0001 \\
\hline Trade school/college/university & $553(19.1)$ & $723(24.5)$ & & \\
\hline $9-12$ years & $799(27.5)$ & $924(31.4)$ & & \\
\hline$\leq 8$ years & $1546(53.4)$ & $1300(44.1)$ & & \\
\hline Income & & & 10.72 & 0.0047 \\
\hline Higher & $1021(35.3)$ & $1157(39.2)$ & & \\
\hline Middle & $928(32.0)$ & $907(30.8)$ & & \\
\hline Lower & $941(32.7)$ & $875(30.0)$ & & \\
\hline Single or divorced, n (\%) & $366(12.6)$ & $197(6.7)$ & 58.81 & 0.0001 \\
\hline General stress, n (\%) & & & 20.33 & 0.0001 \\
\hline Permanent & $1083(37.4)$ & $944(32.0)$ & & \\
\hline Several periods & $1311(45.3)$ & $1411(47.9)$ & & \\
\hline Never experienced & $500(17.3)$ & $591(20.1)$ & & \\
\hline Depressed, n (\%) & $559(19.6)$ & $273(9.3)$ & 122.88 & 0.0001 \\
\hline Consumption of vegetables (times/week) & $7.8(5.5)$ & $7.9(5.4)$ & -1.10 & 0.2705 \\
\hline Consumption of fruits (times/week) & $4.0(3.7)$ & $4.8(3.7)$ & -9.29 & 0.0001 \\
\hline
\end{tabular}

$N$, number; $p$-value, significance of difference between group means and frequency determined by rank-test and chi-square test. 
1999 and March 2003 from 27 regions in China. Characteristics of Participants were shown in Table 1. History of hypertension, diabetes and stroke, smoking, education status, income, general stress, dietary frequency and both higher WHR and BMI levels were significant determinants of AMI in this population.

Age-, sex- and area-adjusted and multivariable adjusted Odds ratio (OR) for AMI risk factors are presented in Table 2. After adjustment for age and sex, the OR associated with nap after lunch, compared with no nap was 1.06 (95\% CI: 0.96 to 1.18). The model adjusted for all variables, the ORs were 0.94 (95\% CI: 0.84 to 1.07).

After adjustment for age and sex, the OR associated with snoring everyday, compared with no snoring was 2.06 (95\% CI: 1.61 to 2.63), for 3-5 times per week group was 2.50 (95\% CI: 2.02 to 3.11 ), for $1-3$ times per week group was 1.40 (95\% CI: 1.21 to 1.62 ), and for $0-1$ time per week group was 1.06 (95\% CI: 0.91 to 1.24$)$. After adjustment for age, sex, area, whr, bmi, smoking, drinking, physical activity, consumption of vegetables and fruits, these estimates were slightly decreased (OR: 1.80, 95\% CI: 1.39 to 2.33 for everyday group; OR: 2.20 , 95\% CI: 1.75 to 2.77 for 3-5 times per week group; OR: 1.29, 95\% CI: 1.11 to 1.50 for 3-5 1-3 times per week; OR: $0.94,95 \% \mathrm{CI}: 0.80$ to 1.10 for $0-1$ time per week group). In the final model, adjusted for all the risk factors, and the OR for everyday group and 3-5 times per week group was 1.45 (95\% CI: 1.01 to 1.91 ) and 1.93 (95\% CI: 1.52-2.46) compared to no snoring group.
In age-, sex- and area-adjusted analysis of snoring severity (Table 2), people in the highest level (serious snoring) had an OR of 2.70 (95\% CI: 2.03 to 3.59; $P$ value $=$ 0.0001) compared with those in the lowest level (no snoring). The association remained similar in multivariate analysis. After adjustment for age, sex, area, educational status, household income, marital status, stress and depression, OR associated with serious level group was 2.65, compared with no snoring group. After adjustment for age, sex, area, whr, bmi, smoking, drinking, physical activity, consumption of vegetables and fruits, with serious level group having an 20\% decreased risk compared with the no snoring group $(\mathrm{OR}=2.18 ; 95 \%$ CI: 1.62 to $2.95 ; P$ value $=0.0001)$. In final analysis adjusted for all the risk factors, the OR for serious level group and moderate group was 1.77 (95\% CI: 1.29 to 2.43) and 1.37 (95\% CI: 1.10 to 1.69 ) compared to no snoring group. People having serious snoring increased $77 \%$ risk of AMI.

The association of time of sleep and AMI are presented in Table $3.67 .4 \%$ people in control group have $6-8$ hours sleeping, compared with $62.2 \%$ in AMI group ( $P$-value, 0.0002). $15.2 \%$ people in control group have $\leq 6$ hours sleeping, compared with $17.4 \%$ in AMI group.

Age-, sex- and area-adjusted and multivariable adjusted Odds ratio (OR) for snoring associated factors were presented in Table 4. After adjustment of all other variables, BMI, hypertension, smoking, and general stress were associated with AMI.

Table 2 Odds Ratios (95\% confidence intervals) for Acute Myocardial Infarction (AMI) risk for sleep and snoring with different levels of adjustments

\begin{tabular}{|c|c|c|c|c|c|c|c|}
\hline Sleep and snoring & Case (\%) & Control (\%) & $\begin{array}{l}\text { Odds ratio } \\
(95 \% \mathrm{Cl})^{*}\end{array}$ & $\begin{array}{l}\text { Adjusted OR } \\
\qquad(95 \% \mathrm{Cl})^{\dagger}\end{array}$ & $\begin{array}{l}\text { Adjusted OR } \\
\qquad(95 \% \mathrm{Cl})^{\ddagger}\end{array}$ & $\begin{array}{l}\text { Adjusted OR } \\
(95 \% \mathrm{CI})^{\S}\end{array}$ & $\begin{array}{l}\text { Adjusted OR } \\
\qquad(95 \% \mathrm{Cl})^{\|}\end{array}$ \\
\hline \multicolumn{8}{|l|}{ Nap after lunch } \\
\hline No & $1384(47.8)$ & $1488(50.5)$ & 1.00 & 1.00 & 1.00 & 1.00 & 1.00 \\
\hline Yes & $1510(52.2)$ & $1458(49.5)$ & $1.06(0.96-1.18)$ & $1.00(0.89-1.11)$ & $1.05(0.94-1.17)$ & $1.00(0.89-1.11)$ & $0.94(0.84-1.07)$ \\
\hline \multicolumn{8}{|l|}{ Snoring frequency } \\
\hline No snoring & $546(19.2)$ & $725(25.0)$ & 1.00 & 1.00 & 1.00 & 1.00 & 1.00 \\
\hline 0-1 time per week & $635(22.4)$ & $796(27.4)$ & $1.06(0.91-1.24)$ & $1.08(0.92-1.26)$ & $0.94(0.80-1.10)$ & $1.06(0.90-1.24)$ & $0.94(0.80-1.12)$ \\
\hline 1-3 times per week & 1115 (39.3) & 1069 (36.8) & $1.40(1.21-1.62)$ & $1.33(1.15-1.55)$ & $1.29(1.11-1.50)$ & $1.37(1.18-1.60)$ & $1.20(1.02-1.42)$ \\
\hline$>3$ times per week & $542(19.1)$ & $313(10.8)$ & $2.31(1.93-2.76)$ & $1.92(1.59-2.31)$ & $2.03(1.67-2.46)$ & $2.17(1.80-2.62)$ & $1.72(1.40-2.11)$ \\
\hline \multicolumn{8}{|l|}{ Snoring severity } \\
\hline No snoring & $532(19.4)$ & $732(26.1)$ & 1.00 & 1.00 & 1.00 & 1.00 & 1.00 \\
\hline Mild & 1647 (59.9) & $1685(60.1)$ & 1.35 (1.18-1.54) & $1.32(1.14-1.51)$ & $1.22(1.06-1.41)$ & $1.33(1.16-1.53)$ & $1.16(1.00-1.35)$ \\
\hline Moderate & $404(14.7)$ & $298(10.6)$ & $1.87(1.55-2.26)$ & $1.60(1.32-1.95)$ & $1.66(1.36-2.03)$ & $1.77(1.45-2.15)$ & $1.37(1.10-1.69)$ \\
\hline Serious & $166(6.0)$ & 87 (3.1) & $2.70(2.03-3.59)$ & $2.08(1.55-2.80)$ & $2.18(1.62-2.95)$ & $2.65(1.98-3.55)$ & $1.77(1.29-2.43)$ \\
\hline
\end{tabular}

*Model adjusted for age, sex and area.

${ }^{\dagger}$ Model adjusted for age, sex, area, hypertension, diabetes, stroke and family history of MI.

${ }^{\ddagger}$ Model adjusted for age, sex, area, whr, bmi, smoking, drinking, physical activity, consumption of vegetables and fruits.

${ }^{\S}$ Model adjusted for age, sex, area, educational status, household income, marital status, stress and depression.

"Model adjusted for all the risk factors. 
Table 3 Sleep duration difference between Acute Myocardial Infarction (AMI) participants and controls

\begin{tabular}{ccccc}
\hline Nap and sleep duration & AMI cases & Controls & $\boldsymbol{X}^{2}$ & $P$-value \\
\hline Nap duration (minutes) & $N=1509$ & $N=1455$ & 25.42 & 0.0001 \\
$\leq 30$ & $384(25.5)$ & $489(33.6)$ & & \\
$30-60$ & $791(52.4)$ & $704(48.4)$ & & \\
$>60$ & $334(22.1)$ & $262(18.0)$ & & \\
Sleep duration (hours) & $N=2873$ & $N=2918$ & 17.09 & 0.0002 \\
$\leq 6$ & $499(17.4)$ & $444(15.2)$ & & \\
$6-8$ & $1787(62.2)$ & $1966(67.4)$ & & \\
$>8$ & $587(20.4)$ & $508(17.4)$ & & \\
\hline
\end{tabular}

$N$, number; $p$-value, significance of difference between group frequency determined by chi-square test.

Table 5 showed the interaction between snoring frequency and related factors of AMI in the INTERHEART China study. The interaction between levels of snoring frequency and permanent stress was significant $(P$ value for interaction, 0.0155).

Figure 1 showed the association of snoring frequency with risk for AMI in men versus women. In models adjusted for all the risk factors, OR associated with snoring frequency (3-5 times per week group, compared to no snoring group), was 2.26 (95\% CI: 1.30 to
3.92) in women, 1.90 (95\% CI: 1.44 to 2.50 ) in men, ( $p$ value for heterogeneity, 0.1059). The effect of snoring was stronger in younger population; the OR associated with snoring frequency (everyday group, compared to no snoring group), was 1.88 (95\% CI: 1.25 to 2.83 ) in younger, 1.18 (95\% CI: 0.81 to 1.73$)$ in older. $p$-value was significant; $p=0.0201$.

\section{Discussion}

In the present analysis, we evaluated the association between categories of sleep duration and snoring frequency as well as the duration of activity with AMI risk factors and to the risk of developing an AMI.

We observed an inverse association between serious snoring frequency and AMI risk after controlling for similar demographic and potential confounders. People having serious snoring increased $77 \%$ risk of AMI. Our results found that there was an increased risk for CVD in China population who slept less than 6 hours or more than 8 hours per day when compared with those who sleep 6 to 8 hours per day. Another study found that the odds of sleeping less than 6 hours per night was lower for women and married persons [14]. The Nurse's Health Study found a modest relationship between coronary events and sleeping 6 hours or less compared with 8 hours

Table 4 Associations between Snoring and Acute Myocardial Infarction (AMI) risk factors

\begin{tabular}{|c|c|c|c|}
\hline \multirow[t]{2}{*}{ AMI related factors } & \multicolumn{3}{|c|}{ Snoring $(\mathrm{Y} / \mathrm{N})$} \\
\hline & $P$ value ${ }^{*}$ & $\begin{array}{l}\text { Odds ratio } \\
(95 \% \mathrm{Cl})^{*}\end{array}$ & $\begin{array}{c}\text { Adjusted } \\
\text { OR }(95 \% \mathrm{Cl})^{\dagger}\end{array}$ \\
\hline Sex (Male vs Female) & 0.0002 & $1.40(1.18-1.68)$ & $1.43(1.14-1.79)$ \\
\hline BMl & 0.0001 & & \\
\hline$\leq 24$ & & 1.00 & 1.00 \\
\hline $24-28$ & & $1.79(1.49-2.14)$ & $1.80(1.48-2.18)$ \\
\hline$>28$ & & $2.53(1.82-3.51)$ & $2.51(1.75-3.58)$ \\
\hline Hypertension (Yes vs No) & 0.0001 & $1.84(1.47-2.30)$ & $1.52(1.17-1.97)$ \\
\hline Diabetes (Yes vs No) & 0.9045 & $1.03(0.63-1.70)$ & $0.88(0.50-1.52)$ \\
\hline Stroke (Yes vs No) & 0.0332 & $1.80(1.05-3.09)$ & $0.83(0.46-1.50)$ \\
\hline family history of Ml (Yes vs No) & 0.8834 & $1.05(0.56-1.97)$ & $1.13(0.57-2.24)$ \\
\hline Smoking (Yes vs No) & 0.0001 & $1.89(1.58-2.27)$ & $1.88(1.51-2.34)$ \\
\hline Alcohol (Yes vs No) & 0.0002 & $1.66(1.27-2.17)$ & $1.30(0.97-1.76)$ \\
\hline Physical activity (Yes vs No) & 0.6928 & $0.96(0.77-1.19)$ & $1.10(0.86-1.39)$ \\
\hline Single or divorced (Single vs married) & 0.0004 & $0.58(0.42-0.78)$ & $0.57(0.40-0.81)$ \\
\hline General stress & 0.0001 & & \\
\hline Permanent & & 1.00 & 1.00 \\
\hline Several periods & & $2.13(1.73-2.63)$ & $1.89(1.49-2.38)$ \\
\hline Never experienced & & $2.31(1.83-2.90)$ & $2.16(1.67-2.79)$ \\
\hline Depressed (Yes vs No) & 0.2133 & $0.83(0.63-1.11)$ & $0.92(0.68-1.26)$ \\
\hline
\end{tabular}

${ }^{*}$ Calculated by Chi-squire test.

*Univariate association analysis by logistic regression.

${ }^{\dagger}$ Model adjusted for all the risk factors. 
Table 5 Interaction between snoring frequency and other related factors of AMI

\begin{tabular}{|c|c|c|c|c|c|}
\hline & No snoring & 0-1 time per week & 1-3 times per week & $>3$ times & $P$-value for interaction \\
\hline Age (years), mean (SD) & & & & & 0.0133 \\
\hline Case & $62.5(12.4)$ & $61.8(11.1)$ & $62.5(11.7)$ & $60.9(11.4)$ & \\
\hline Control & $59.5(12.7)$ & $59.9(10.5)$ & $61.0(11.4)$ & $60.5(11.0)$ & \\
\hline BMI (kg/m2), mean (SD) & & & & & 0.7755 \\
\hline Case & $24.0(3.4)$ & $24.5(3.4)$ & $24.8(3.1)$ & $25.6(3.3)$ & \\
\hline Control & $23.6(3.0)$ & $24.7(2.7)$ & $24.6(2.8)$ & $25.3(3.9)$ & \\
\hline WHR, mean (SD) & & & & & 0.0179 \\
\hline Case & $0.87(0.08)$ & $0.89(0.07)$ & $0.86(0.09)$ & $0.91(0.08)$ & \\
\hline Control & $0.88(0.08)$ & $0.89(0.08)$ & $0.86(0.09)$ & $0.90(0.07)$ & \\
\hline Hypertension, n (\%) & & & & & 0.2176 \\
\hline Case & $190(34.8)$ & $198(31.2)$ & $450(40.4)$ & $289(53.3)$ & \\
\hline Control & $111(15.3)$ & $153(19.2)$ & $286(26.8)$ & 105 (33.6) & \\
\hline Diabetes, $n(\%)$ & & & & & 0.8630 \\
\hline Case & $58(10.6)$ & $63(9.9)$ & $153(13.7)$ & $76(14.0)$ & \\
\hline Control & $21(2.9)$ & $18(2.3)$ & $35(3.3)$ & $12(3.8)$ & \\
\hline Stroke, $n(\%)$ & & & & & 0.2193 \\
\hline Case & $42(7.7)$ & $54(8.5)$ & 155 (13.9) & $63(11.7)$ & \\
\hline Control & $16(2.2)$ & $19(2.4)$ & $47(4.4)$ & $19(6.1)$ & \\
\hline Current smokers, $n(\%)$ & & & & & 0.1616 \\
\hline Case & $242(44.3)$ & $356(56.1)$ & $655(58.7)$ & $404(74.5)$ & \\
\hline Control & $214(29.5)$ & $325(40.8)$ & $462(43.2)$ & $176(56.2)$ & \\
\hline Alcohol consumption ( $\geq 1 /$ week), $n(\%)$ & & & & & 0.8611 \\
\hline Case & $50(9.2)$ & $85(13.4)$ & $198(17.8)$ & $121(22.3)$ & \\
\hline Control & $74(10.2)$ & $82(10.3)$ & $186(17.4)$ & $78(24.9)$ & \\
\hline Physical activity, $n$ (\%) & & & & & 0.7550 \\
\hline Case & $93(17.0)$ & $65(10.3)$ & $122(11.0)$ & $132(24.4)$ & \\
\hline Control & $137(18.9)$ & $117(14.7)$ & $196(18.3)$ & $84(27.0)$ & \\
\hline Education ( $\leq 8$ years), $n$ (\%) & & & & & 0.5209 \\
\hline Case & $292(53.5)$ & $340(53.6)$ & $631(56.6)$ & $253(46.7)$ & \\
\hline Control & $308(42.5)$ & $343(43.3)$ & $520(48.6)$ & $114(36.4)$ & \\
\hline Low family income, $n(\%)$ & & & & & 0.8004 \\
\hline Case & $188(34.6)$ & $200(31.6)$ & $323(31.7)$ & $175(32.4)$ & \\
\hline Control & $221(30.7)$ & $242(30.4)$ & $321(30.1)$ & $76(24.3)$ & \\
\hline Permanent stress, $n(\%)$ & & & & & 0.0148 \\
\hline Case & $199(36.5)$ & $262(41.3)$ & $399(35.8)$ & $193(35.7)$ & \\
\hline Control & $194(26.8)$ & $263(33.0)$ & $369(34.6)$ & $101(32.3)$ & \\
\hline Depression, $n(\%)$ & & & & & 0.5744 \\
\hline Case & $113(21.3)$ & $118(18.9)$ & $179(16.2)$ & $127(23.8)$ & \\
\hline Control & $75(10.5)$ & $70(8.9)$ & $77(7.3)$ & $45(14.4)$ & \\
\hline Vegetables consumption, (times/week), mean (SD) & & & & & 0.0001 \\
\hline Case & $7.1(5.3)$ & $6.6(5.0)$ & $8.2(5.5)$ & $9.3(6.0)$ & \\
\hline Control & $7.7(5.5)$ & $7.5(4.9)$ & $8.3(5.4)$ & $8.4(5.8)$ & \\
\hline
\end{tabular}


Table 5 Interaction between snoring frequency and other related factors of AMI (Continued)

\begin{tabular}{lllll}
\hline Fruit consumption, (times/week), mean (SD) & & & & \\
Case & $3.5(3.5)$ & $3.5(3.2)$ & $4.5(3.5)$ & $4.2(4.4)$ \\
Control & $4.4(4.0)$ & $4.5(3.3)$ & $5.3(3.5)$ & $4.6(3.8)$ \\
\hline
\end{tabular}

(OR, 1.18; 95\% CI, 0.98-1.42) [5]. In a Japanese population, less than 6 hours of sleep was associated with a significant 2-fold increase in CVD events in men and a non significant trend in women [4]. Our data are consistent with those of the National Health Interview Survey that showed that sleep duration was a significant predictor of CVD independent of age, gender, and race/ethnicity [2]. Lack of sleep has been linked to several CVD traditional and psychosocial risk factors, as observed in our study. Previous research has shown that sleep deprivation results in decreased glucose tolerance and elevated blood pressure [2].

In the present prospective study, snoring frequency was associated with an increased incidence of cardiovascular events among community-dwelling middle-aged Japanese women. This association was independent of age and other confounding factors. As compared with never snorers, 'everyday snoring' women had a 2.5-fold higher risk of cardiovascular events during 6 years of follow-up. The association of everyday snoring with cardiovascular events was attenuated after adjustment for BMI and after further adjustment for systolic blood pressure, antihypertensive medication use, diabetes mellitus, and hypercholesterolemia. This suggested that overweight partly mediated the association and that hypertension and metabolic abnormalities partly caused by snoring contribute to the risk of cardiovascular events in women who snore every day. This is the first study to show a relationship between habitual snoring and risk of cardiovascular events among a population in Asia, which has a low prevalence of obesity. The biological mechanisms that link habitual snoring to the development of cardiovascular disease remain to be fully elucidated, but a number of mechanisms have been proposed. Habitual snoring is often accompanied by sleep apnea or hypopnea. Repetitive episodes of intermittent complete and partial airway collapse during sleep result in hypoxemia, hypercapnia, changes in intrathoracic pressure, and repeated arousal from sleep. Episodes of snoring and apneic events can cause acute hemodynamic changes (such as increased cardiac output, enhanced cardiac arrhythmia, patent foramen ovale appearance, increased intracranial pressure, and decreased cerebral blood flow) [25], increased platelet aggregation and fibrinogen concentrations [26,27], and decreased

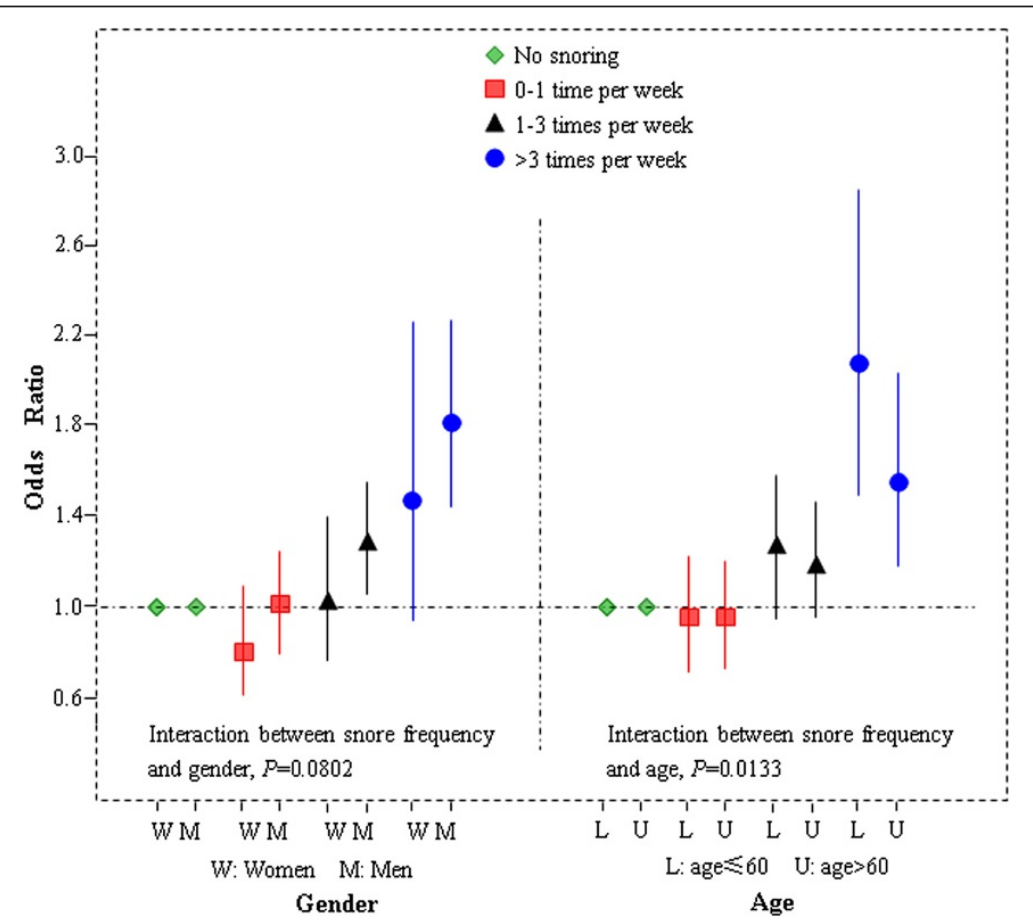

Figure 1 Adjusted odds ratios (and 95\% confidence intervals), with tests for heterogeneity for risk of acute myocardial infarction for snore frequency by different type of gender and age. 
fibrinolysis, which directly affect the cardiovascular system. Abnormal metabolic conditions such as hypertension, diabetes mellitus, and hypercholesterolemia may also increase the risk of cardiovascular disease via elevation of sympathetic activation, oxidative stress [28-30], activation of the hypothalamic-pituitary-adrenal axis due to sleep fragmentation, and endothelial dysfunction [31-33].

In our study, we observed snoring frequency was more significant associated with AMI in men, compared to women in China population. In contrast to the significant association of habitual snoring with cardiovascular events in women, no such association was observed in men. Large population-based prospective studies of middleaged men, women, and a population of men and women aged 20 years or older have reported positive associations between habitual snoring and cardiovascular events $[21,22]$. However, no study has reported a sex difference in the association. Recent reports from the Sleep Heart Health Study (a large population-based study of American residents aged 40 or older) have noted sex differences in the association between SDB, as defined by the apnea-hypopnea index (AHI), and the risk of coronary heart disease, heart failure, and stroke $[34,35]$. The multivariable HRs associated with a 10-unit increase in AHI were 1.1 (1.0-1.3) for incident heart failure in men and 1.1 (1.0-1.2) for incident coronary heart disease in men aged 70 years or younger, whereas no such associations were observed in women [21]. Similarly, the multivariable HR for ischemic stroke incidence was 2.9 (1.1-7.4) in men and $1.2(0.7-2.2)$ in women for the highest $(>19)$ as compared with the lowest $(\leq 4)$ AHI quartiles [22]. The reasons for the present lack of association between habitual snoring and risk of cardiovascular events in men are unknown. We found stronger association in men than women when the analysis was stratified by age, smoking, or drinking status. Further research is necessary to elucidate this sex difference.

Several limitations of this study should be considered. First, a large potential disadvantage was that this control population may not be representative of the general Chinese population, nor were the AMI cases representative of all Chinese AMI patients. And all the individuals were drawn from urban communities, so the study results may not necessarily apply to rural regions. Other potential sources of bias in our investigation include the selection of controls and a differential recall among cases compared with control subjects. While the use of population based controls would be ideal, we addressed selection bias that may arise with use of hospital-based controls by obtaining control subjects from other different outpatient clinics and inpatient wards in the hospital. Therefore, if an association exists between the exposure of interest and the disease status of one control group, the bias that may result would be diluted. Additionally, we used a systematic method of control selection that would avoid arbitrary selection of controls within wards and clinics. Differential recall of sleep duration and snoring frequency is also a potential concern; however, research assistants asked case subjects to specifically report on their level of sleep duration and snoring frequency prior to their myocardial infarction. While the potential for recall bias may exist, awareness of heart disease prevention and health consciousness may not be as high among our study population in China as its is in Western countries; hence the likelihood of recall bias may be lower. We also excluded all those with any prior heart disease from the study. As well, while we cannot exclude the possibility that not all sleep and snoring condition was reported, interviewers were trained to conduct thorough interviews on sleep and snoring during the day or night. While future prospective research within China will adequately address these biases, the case-control design had the advantage of being cost, resource, and time efficient.

In the further research, we need to determine the mechanisms of this association exactly. New study designs and methods need to be developed. Testing the theoretical models of potential mechanisms is highly dependent on the quality of study design and the data that results. One serious problem with the existing studies is retrospective. New epidemiological methods have been developed to overcome or evaluate some existing problems. The prospective research about the impact of physical activities on health outcomes at different economic development levels is currently being studied in the Prospective Urban Rural Epidemiologic study (PURE study) [36-38]. Further, there may be heterogeneity between physical activities and health outcomes across different populations through 20 years follow-up. In PURE study, more fine measures of physical activities during the life course are needed.

\section{Conclusions}

Snoring frequency, including as much as everyday and 3-5 times per week, was positively associated with AMI risk and less sleep duration was associated with risk of AMI. Less sleep time could increase AMI risk in China population.

\section{Competing interests}

The INTERHEART study was funded through unrestricted grants from several pharmaceutical companies (with major contributions from AstraZeneca, Novartis, Hoechst Marion Roussel (now Aventis), Knoll Pharmaceuticals (now Abbott), Bristol Myers Squibb, King Pharma and Sanofi-Sythelabo).

\section{Authors' contributions}

DX carried out the analysis of association between snoring and AMI studies, participated in INTERHEART China study. YW and HG performed the statistical analysis. SY and KT participated in the design of the study. WL and $\mathrm{LL}$ conceived of the study, and participated in its design and coordination and helped to draft the manuscript. All authors read and approved the final manuscript. 


\section{Acknowledgements}

We are thankful for all the INTERHEART China Study Investigators: Chen Xiao-chun (Baotou), Dong Guoxiong (Qingdao), Fu Qiang (Xuzhou), Huang Jian (Xi'an), Hui Rutai (Beijing), Jiang Baogi (Beijing), Li Jianjun (Wuhan), Li Ximing (Nanjing), Li Xun (Liaocheng), Li Yu (Shenyang), Li Zhanquan (Shenyang), Liao Yuhua (Wuhan), Liu Xinshan (Zhengzhou), Ma Aiqun (Xi'an), Wan Zheng (Tianjin), Wang Daowen (Wuhan), Wang Fengzhen (Taian), Wang X (Yangquan), Wei Yu (Chaoyang), Xu Tie (Xuzhou), Zhang Lin (Beijing), Zhang Yanzhen (Weifang), Zhao Ruiping (Baotou), Zhou Changyong (Qingdao) and Zhu Xinglei (Jinan).

The INTERHEART China study was funded by the Canadian Institute of Health Research, the Heart and Stroke Foundation of Ontario, the International. Clinical Epidemiology Network (INCLEN), and through unrestricted grants from several pharmaceutical companies (with major contributions from AstraZeneca, Novartis, Hoechst Marion Roussel (now Aventis), Knoll Pharmaceuticals (now Abbott), Bristol Myers Squibb, King Pharma and Sanofi-Sythelabo).

\section{Author details}

'Division of Biometrics, National Center for Cardiovascular Diseases, Cardiovascular Institute \& Fu Wai Hospital, Peking Union Medical College \& Chinese Academy of Medical Sciences, Beijing 100037, China. ${ }^{2}$ Beijing Hypertension League Institute, Beijing 100039, China. ${ }^{3}$ Population Health Research Institute, McMaster University, Hamilton, Canada.

Received: 28 January 2014 Accepted: 23 May 2014 Published: 29 May 2014

\section{References}

1. Yusuf S, Reddy S, Ounpuu S, Anand S: Global burden of cardiovascular disease, part I: general considerations, the epidemic transition, risk factors, and impact of urbanization. Circulation 2001, 104:2746-2753.

2. Sabanayagam C, Shanka A: Sleep duration and cardiovascular disease: results from the National Health Survey. Sleep 2010, 33:1037-1042.

3. Ikehara S, Iso H, Date C, Kikuchi S, Watanabe Y, Wada Y, Inaba Y, Tamakoshi A, JACC Study Group: Association of sleep duration with mortality from cardiovascular disease and other causes for Japanese men and women: the JACC study. Sleep 2009, 32:295-301.

4. Amagai Y, Ishikawa S, Gotoh T, Kayaba K, Nakamura Y, Kajii E: Sleep duration and incidence of cardiovascular events in a Japanese population: the Jichi Medical School cohort study. J Epidemiol 2010 20:106-110

5. Ayas NT, White DP, Manson JE, Stampfer MJ, Speizer FE, Malhotra A, Hu FB: A prospective study of sleep duration and coronary heart disease in women. Arch Inter Med 2003, 163:205-209.

6. Qureshi A, Giles WH, Croft JB, Bliwise DL: Habitual sleep patterns and risk for stroke and coronary heart disease: a 10-year follow-up from NHANES I. Neurology 1997, 48:904-911.

7. Spiegel K, Knutson K, Leproult R, Tasali E, Van Cauter E: Sleep loss: a novel risk factor for insulin resistance and type 2 diabetes. J Appl Physiol 2005, 99(5):2008-2019.

8. Cappuccio FP, D'Elia L, Strazzullo P, Miller MA: Quantity and quality of sleep and incidence oftype 2 diabetes: a systematic review and meta-analysis. Diabetes Care 2010, 33:414-420

9. Gangwisch JE, Heymsfield SB, Boden-Albala B, Buijs RM, Kreier F, Pickering TG, Rundle AG, Zammit GK, Malaspina D: Short sleep duration as a risk factor for hypertension: analyses of the first National Health and Nutrition Examination Survey. Hypertension 2006, 47:833-839.

10. Cappuccio FP, D'Elia L, Strazzullo P, Miller MA: Sleep duration and all-cause mortality: asystematic review and meta-analysis of prospective studies. Sleep 2010, 33:585-592.

11. Gallicchio L, Kalesan B: Sleep duration and mortality: a systematic review and meta-analysis. J Sleep Res 2009, 18:148-158.

12. Ferrie JE, Shipley MJ, Cappuccio FP, Brunner E, Miller MA, Kumari M, Marmot MG: A prospective study of change in sleep duration: associations with mortality in the Whitehall II cohort. Sleep 2007, 30:1659-1666.

13. Patel SR, Ayas NT, Malhotra MR, White DP, Schernhammer ES, Speizer FE, Stampfer MJ, Hu FB: A prospective study of sleep duration and mortality risk in women. Sleep 2004, 27:440-444.
14. Knutson KL, Cauter EV, Rathouz JP, DeLeire TD, Lauderdale DS: Trends in the prevalence of short sleepers in the USA: 1975-2006. Sleep 2010, 33:37-45.

15. Knutson KL, Spiegel K, Penev P, Van Cauter E: The metabolic consequences of sleep deprivation. Sleep 2007, 11:163-178.

16. Gangwisch JE: Epidemiological evidence for the links between sleep, circadian rhythms and metabolism. Obes Rev 2009, 10:37-45.

17. Koskenvuo M, Kaprio J, Partinen M, Langinvainio H, Sarna S, Heikkila K: Snoring as a risk factor for hypertension and angina pectoris. Lancet 1985, 1:893-896.

18. Dunai A, Keszei AP, Kopp MS, Shapiro CM, Mucsi I, Novak M: Cardiovascular disease and health-careutilization in snorers: apopulationsurvey. Sleep 2008, 31:411-416.

19. Yaggi H, Mohsenin V: Obstructive sleep apnoea and stroke. Lancet Neurol 2004, 3:333-342.

20. Hu FB, Willett WC, Manson JE, Colditz GA, Rimm EB, Speizer FE, Hennekens $\mathrm{CH}$, Stampfer MJ: Snoring and risk of cardiovascular disease in women. J Am Coll Cardiol 2000, 35:3081-3083.

21. Koskenvuo M, Kaprio J, Telakivi T, Partinen M, Heikkila K, Sarna S: Snoring as a risk factor for ischaemic heart disease and stroke in men. Br Med J (Clin Res Ed) 1987, 294:169.

22. Erlichman J, Kerbey AL, James WP: Physical activity and its impact on health out-comes. Paper 1: The impact of physical activity on cardiovascular disease and all-cause mortality: an historical perspective. Obes Rev 2002, 3:257-271.

23. Hu G, Tuomilehto J, Silventoinen K, Barengo NC, Peltonen M, Jousilahti P. The effects of physical activity and body mass index on cardiovascular, cancer and all-cause mortality among 47212 middle-aged Finnish men and women. Int J Obes (Lond) 2005, 29:894-902.

24. Katzmarzyk PT, Janssen I, Ardern Cl: Physical inactivity, excess adiposity and pre-mature mortality. Obes Rev 2003, 4:257-290.

25. Franklin KA: Cerebral haemo dynamics in obstructive sleep apnoea and Cheyne-Stokes respiration. Sleep Med Rev 2002, 6:429-441.

26. Bokinsky G, Miller M, Ault K, Husband P, Mitchell J: Spontaneous platelet activation and aggregation during obstructive sleep apnea and its response to therapy with nasalcontinuouspositiveairwaypressure. Apreliminary investigation. Chest 1995, 108:625-630.

27. Wessendorf TE, Thilmann AF, Wang YM, Schreiber A, Konietzko N, Teschler $\mathrm{H}$ : Fibrinogen level sand obstructive sleep apnea in ischemic stroke. Am J Respir Crit Care Med 2000, 162:2039-2042.

28. Narkiewicz K, vande Borne PJ, Montano N, Dyken ME, Phillips BG, Somers VK: Contribution of to nicchemoreexfl activation to sympathetic activity and blood pressure in patients with obstructive sleep apnea. Circulation 1998, 97:943-945.

29. Nonogaki K: New insights into sympathetic regulation of glucose and fatmetabolism. Diabetologia 2000, 43:533-549.

30. Ciftci TU, Kokturk O, Bukan N, Bilgihan A: The relation ship between serumcy to kine levels with obesity and obstructive sleep apnea syndrome. Cytokine 2004, 28:87-91.

31. Follenius M, Brandenberger G, Bandesapt JJ, Libert JP, Ehrhart J: Nocturnal cortisol release in relation to sleep structure. Sleep 1992, 15:217.

32. Stamatakis KA, Punjabi NM: Effects of sleep fragmentation on glucose metabolism in normal subjects. Chest 2010, 137:95-101.

33. Atkeson A, Jelic S: Mechanisms of endothelialdys function in obstructive sleep apnea. Vasc Health Risk Manag 2008, 4:1327-1335.

34. Gottlieb DJ, Yenokyan G, Newman AB, OConnor GT, Punjabi NM, Quan SF, O'Connor GT, Punjabi NM, Quan SF, Redline S, Resnick HE, Tong EK, Diener-West M, Shahar E: Prospective study of obstructive sleep apnea and incident coronary heart disease and heart failure: the Sleep Heart Health Study. Circulation 2010, 122:352-360.

35. Goldstein C, Zee PC: Obstructive sleep apnea-hypopnea and incident stroke: the Sleep Heart Health Study. Am J Respir Crit Care Med 2010, 182:269-277.

36. Teo K, Chow CK, Vaz M, Rangarajan S, Yusuf S: PURE Investigators-Writing Group. The Prospective Urban Rural Epidemiology (PURE) study: Examining the impact of societal influences on chronic noncommunicable diseases in low-, middle-, and high-income countries. Am Heart J 2009, $158: 1-7$

37. Yusuf S, Hawken S, Ounpuu S, Dans T, Avezum A, Lanas F, McQueen M, Budaj A, Pais P, Varigos J, Lisheng L, INTERHEART Study Investigators: Effect of potentially modifiable risk factors associated with myocardial 
infarction in 52 countries (the INTERHEART study): case-control study. Lancet 2004, 364:937-952.

38. Iqbal R, Anand S, Ounpuu S, Islam S, Zhang X, Rangarajan S, Chifamba J, Al-Hinai A, Keltai M, Yusuf S, INTERHEART Study Investigators: Dietary patterns and the risk of acute myocardial infarction in 52 Countries: results of the INTERHEART Study. Circulation 2008, 118:1929-1937.

doi:10.1186/1471-2458-14-531

Cite this article as: Xie et al:: Sleep duration, snoring habits and risk of acute myocardial infarction in China population: results of the INTERHEART study. BMC Public Health 2014 14:531.

\section{Submit your next manuscript to BioMed Central and take full advantage of:}

- Convenient online submission

- Thorough peer review

- No space constraints or color figure charges

- Immediate publication on acceptance

- Inclusion in PubMed, CAS, Scopus and Google Scholar

- Research which is freely available for redistribution 